\title{
A Comparison of Clinical Outcomes with Regular- and Low- Profile Totally Implanted Central Venous Port Systems
}

Ulf Karl-Martin Teichgräber · Florian Streitparth •

Chie Hee Cho · Thomas Benter · Bernhard Gebauer

Published online: 28 March 2009

(C) Springer Science+Business Media, LLC 2009

Erratum to: Cardiovasc Intervent Radiol

DOI 10.1007/s00270-008-9477-3

An author's name (Florian Streitparth) was misspelled in the print and online versions of this article. The author's name is presented correctly here.

The online version of the original article can be found under doi:10.1007/s00270-008-9477-3.

U. K.-M. Teichgräber $(\bowtie) \cdot$ F. Streitparth

Department of Radiology, Charité Campus Mitte,

Charitéplatz 1, 10115 Berlin, Germany

e-mail: ulf.teichgraeber@charite.de

C. H. Cho · B. Gebauer

Department of Radiology, Charité Campus Virchow-Klinikum,

Augustenburgerplatz 1, 13353 Berlin, Germany

T. Benter

Elblandkliniken Riesa, Weinberstr. 8, 15089 Riesa, Germany 